\title{
Estudo Geológico da Estrutura de Impacto Meteorítico de São Miguel do Tapuio, Piauí - Brasil.
}

\author{
Najlah Zeitoum, Álvaro Penteado Crósta, Ana Maria Góes.
}

\begin{abstract}
Resumo
Estruturas de impacto, ou crateras de impacto, são estruturas formadas devido a colisão de corpos celestes contra outros corpos sólidos. Devido às dificuldades para se identificar e comprovar essas estruturas na Terra, o seu reconhecimento demanda análises detalhadas visando encontrar feições que sejam diagnósticas e/ou indicativas da sua formação. Esta pesquisa teve como objetivo investigar essas feições em amostras coletadas da estrutura de impacto de São Miguel do Tapuio. Analisou-se petrograficamente brechas e arenitos constituídos por distintos graus de deformação, bem como foram identificadas micro-feições de choque diagnósticas.
\end{abstract}

Palavras-chave: SÃO MIGUEL DO TAPUIO, ESTRUTURA DE IMPACTO, MICRO-FEIÇÕES DE CHOQUE.

\section{Introdução}

São Miguel do Tapuio (SMT) é uma estrutura de impacto localizada na margem leste da Bacia do Parnaíba, centrada em $5^{\circ} 37,6^{\prime}$ S e $41^{\circ} 23,3^{\prime}$ W, no estado do Piauí. Trata-se de uma estrutura de morfologia circular de $\sim 20 \mathrm{~km}$ de diâmetro, que exibe uma porção central elevada, bordas ressaltadas e anéis internos concêntricos. A estrutura foi formada em rochas sedimentares do Grupo Serra Grande e nas Formações Pimenteiras e Cabeças do Grupo Canindé. Diversos trabalhos vêm sendo realizados, desde meados dos anos 1970, procurando interpretar a potencial origem dessa estrutura circular. Somente recentemente a estrutura de SMT foi comprovada por Crósta et al. (2018) ${ }^{1}$ ao identificarem micro-feições diagnósticas formadas pelo choque, tais como fraturas planares (planar fractures PFs), feições em pena (feather features - FFs) e feições planares de deformação (planar deformation features PDFs). Com essas evidências, SMT tornou-se a $8^{\text {a }}$ estrutura de impacto confirmada no Brasil e a $2^{\underline{a}}$ maior da América do Sul. Contudo, tal pesquisa foi resultado de uma investigação preliminar das amostras coletadas pelos autores em 2017, as quais ainda demandam outras análises detalhadas. Nesse contexto, a presente pesquisa teve por objetivo descrever petrograficamente as amostras de Crósta et al. (2018)1', e identificar, além das feições diagnósticas do choque, outras deformações que são indicativas do impacto. Embora não sejam diagnósticas, tais características são importantes porque podem revelar importantes transformações que as rochas sedimentares alvo experimentaram em decorrência do impacto.

\section{Resultados e Discussão}

As análises descritivas das amostras se apoiaram na classificação sedimentar petrográfica de Dott $(1964)^{2}$ e Folk $(1980)^{3}$, e as feições de deformação foram investigadas de acordo com French \& Koeberl (2010). Foram analisadas 13 lâminas delgadas em microscópio ótico, confeccionadas a partir das amostras que foram coletadas próximas do núcleo da estrutura. As lâminas, de modo geral, foram identificadas como brechas quartzosas intensamente a moderadamente fraturadas, e arenitos moderadamente a pouco fraturados, com mineralogia essencialmente formada por quartzo. Nas brechas foram observadas intenso fraturamento com fragmentação dos grãos de quartzo, por vezes com textura pulverulenta preenchendo a matriz, sugerindo origem por processos de cominuição nessas rochas. Foram identificadas, também, healed fractures em grãos de quartzo. Já os arenitos exibiram pouco fraturamento dos grãos, os quais, se não formados em regimes de pressão muito baixa do impacto, podem ser devido a eventos diagenéticos comuns na crosta. Desse conjunto, 3 seções delgadas, confeccionadas de uma amostra das brechas, apresentaram micro-feições de choque, incluindo PFs, FFs e PDFs. Tais feições representam formação em regime de alta pressão, entre 2 e $25 \mathrm{GPa}$, pressões estas que só podem ser atingidas em níveis crustais em decorrência de impactos meteoríticos (French, 1998) ${ }^{4}$.

\section{Conclusões}

De acordo com os resultados, verifica-se que as rochas que foram mais deformadas pelo choque, identificadas como brechas quartzosas, são as que apresentaram micro-feições de choque. Tais rochas exibiram intenso fraturamento, cominuição dos grãos e estruturas de healed fractures, cuja intensidade dessas feições não é usualmente encontrada nas rochas sedimentares da Bacia do Parnaíba. Já os arenitos se mostraram menos expostos ao impacto, uma vez que se apresentaram menos afetados pelas deformações. Contudo, é interessante notar a heterogeneidade entre rochas muito e pouco afetadas que ocorrem muito próximas uma da outra. Essas características, em conjunto com as raras ocorrências de micro-feições de choque comprobatórias, demonstram a complexidade geológica atuante em SMT, sugerindo que essa estrutura esteja em um estágio avançado de erosão.

\section{Agradecimentos}

Os autores agradecem à FAPESP pelo apoio financeiro.

${ }^{1}$ Crósta, A.P., Vasconcelos, M.A.R., Reimold, W.U. 2018. Shock deformation confirms the impact origin of the São Miguel do Tapuio structure (PI). In: Congresso Brasileiro de Geologia, 49 ${ }^{\circ}$ Rio de Janeiro. http://cbg2018anais.siteoficial.ws/resumos/4665.pdf.

2 Dott, R. H. 1964. Wacke, graywacke and matrix; what approach to immature sandstone classification?. Journal of Sedimentary Research, 34(3), 625-632.

${ }^{3}$ Folk, R. L. 1980. Petrology of sedimentary rocks. Hemphill Publishing Company.

4 French, B. M., \& Koeberl, C. 2010. The convincing identification of terrestrial meteorite impact structures: What works, what doesn't, and why. Earth-Science Reviews, 98(1-2), 123-170. 